\title{
Teratologías. Figuraciones sirenaicas en la obra de Elizabeth Chorubczyk (Effy Beth) ${ }^{1}$
}

\section{Teratologies. Figurations of mermaids in the work of Elizabeth Chorubczyk (Effy Beth)}

\author{
Pablo Oscar Farneda \\ Universidad de Buenos Aires / coniCET. Buenos Aires, Argentina. \\ pablofarneda@hotmail.com
}

\section{Resumen}

Este artículo aborda y analiza una serie de figuraciones vinculadas a la imagen de la sirena, plasmadas en algunas obras, performances y reflexiones de la artista argentina trans-feminista Effy Beth (1988-2014). Al ser exploradas, estas figuraciones dan cuenta de la experiencia singular de hacerse un cuerpo trans para la artista, con el cual constituir un territorio de existencia posible y habitable. La noción de monstruo (del griego teratos) se despliega en una serie de referencias que van desde la apropiación del término por parte de las prácticas artísticas trans, a las reflexiones filosóficas del pensamiento contemporáneo, y deviene así en un lente a través del cual observar procesos de mutación en los campos subjetivos, sociopolíticos y estéticos.

Palabras clave: sirenas, monstruos, trans, matriz teratológica moderna.

\section{Abstract}

This article discusses a series of figurations linked to the image of the mermaid reflected in some works, performances and reflections of the trans-feminist artist Effy Beth (19882014). These figurations realize the work of make itself a body (that matters), a trans body for the artist, with which constitute existential territory. The notion of monster (gr. teratos) is appropriate for the trans artistic practices but also is explored in the reflections of contemporary philosophy. Thus it becomes a lens to observe processes of mutation in social, political, subjective and aesthetic fields.

Keywords: Sirens, Monsters, Trans, Teratologic-Modern-Matrix.

1 Agradecimientos Proyecto POSTDOC_DICYT, Código 031694PC POSTDOC, Vicerrectoría de Investigación, Desarrollo e Innovación. 
...A la reflexión sobre el monstruo

sobreviene la reflexión del monstruo

El monstruo y su ser, H. Santiesteban

Reivindico mi derecho a ser un monstruo,

¡Y que otros sean lo normal!

Yo monstruo mío, M. Wayar y S. Shock

No existen dos géneros, sólo existe uno, ¡el de cada cual!

Effy Beth

\section{Effy Beth: la gesta del cuerpo propio}

Effy Beth (1988-2014) fue una artista trans-feminista de nacionalidad argentina e israelí, que vivió hasta los cinco años en Israel, y al comienzo de la guerra del Golfo sus padres decidieron volver a Buenos Aires. ${ }^{1}$ En los últimos años, la obra de la artista ha tenido un impacto creciente en los campos tanto del arte contemporáneo como de los activismos queer, trans y de las desobediencias genérico-sexuales. A pesar de su pronto fallecimiento, Chorubczyk produjo durante al menos ocho años una serie de proyectos de performances, obras conceptuales, intervenciones urbanas e intervenciones corporales como parte de su despliegue artístico y político. Participó activamente como performer en las marchas anuales del Orgullo en la ciudad y supo inscribirse en una estela de artistas que cuestionan las categorías sexuales, genéricas, corporales e identitarias desde las prácticas artísticas, cuyos antecedentes recientes en Argentina se remontan a la figura de Batato Barea; además, fue contemporánea de escritoras y performers como Susy Shock y Naty Menstrual.

Su nombre completo, elegido por ella, fue Elizabeth Mía Chorubczyk, y llegó a constar así en su Documento Nacional de Identidad, a pesar de varios conflictos que surgieron por problemas con su doble nacionalidad, incluso después de la aprobación

1 Elizabeth Mía Chorubczyk (Effy Beth) falleció el 26 de marzo de 2014 por decisión propia. Durante más de un año no aparecieron demasiadas referencias y publicaciones sobre su muerte, salvo algunos textos, entrevistas y notas homenajeándola en algunos medios online por parte de amigxs, periodistas y gente vinculada al mundo del arte, el activismo y la militancia. El 13 de septiembre de 2015 su madre Dori Faigenbaum concedió una entrevista al programa radial La Retaguardia, que fue transcrita y publicada en el siguiente sitio: http://www.laretaguardia.com.ar/2015/09/aeffy-no-la-mato-la-sociedad-ella.html. Allí narra experiencias, relatos y reflexiona sobre la muerte de su hija. 
de la Ley de Identidad de Género. De sus dos pasaportes, uno de ellos indicaba su género como masculino (el israelí) y el otro como femenino (el argentino). Aunque declaraba preferir que su sexo no constara en ninguno de los dos, ella se sentía orgullosa de ese desfase.

A través de sus distintas obras de performance, foto y video-performance, blogperformance y textos, ${ }^{2}$ la artista intentaba plasmar no solo sus experiencias respecto al género, la sexualidad y la nacionalidad, que la colocaban -y en las que ella se colocaba- en una zona de indeterminación y extranjería, sino también una práctica que toma como superficie de expresión el cuerpo y los fluidos corporales, en la exploración de un cuerpo trans posible y habitable en tanto territorio singular-colectivo.

Uno de sus proyectos artísticos más renombrados fue la performance en trece actos llamada Nunca serás mujer (2011). ${ }^{3}$ Allí la artista se extrajo medio litro de sangre y la dividió en trece partes para hacerse con cada una de ellas una menstruación: actos performáticos a través de los cuales fue narrando sus experiencias a lo largo del primer año de reasignación hormonal y la asunción de su identidad.

A su vez, las imágenes y figuraciones ligadas a las sirenas encierran una potencia de expresión que la artista utilizó en su exploración acerca de los cuerpos liminales: cuerpos que se encuentran en zonas fronterizas, desapropiados de un territorio claro y definido. La sirena ha sido para Effy una imagen potente y pregnante: un terreno mítico que habilita la posibilidad de ser diferente y singular. Para ella se presenta incluso como un deseo y como uno de sus primeros recuerdos, atraviesa sus relatos desde su infancia en Israel y aparece repetidas veces en sus primeras escrituras:

Tengo un recuerdo fuerte respecto a una infancia llena de deseos: velas de cumpleaños, pestañas sueltas, o sin nada, tan solo cerrar los ojos y pedir. El primer deseo que recuerdo fue con una estrella fugaz, tenía cuatro años y vivía en Israel. Me dijeron nunca contar los deseos hasta que no se cumplan. Yo deseé ser sirena (Beth 2009-2011, episodio 19).

Este relato integra el blog de crónicas íntimas de la artista, llamado Effymine, la serie (2010-2011), y parece, en su misma lógica, dar cuenta de la concreción de dicho deseo: Effy narra lo que ha aprendido de su familia respecto de los deseos, que no deben ser contados hasta que se cumplan, y finalmente narra también el deseo, signo de su realización.

2 Gran parte de su obra se encontró reunida por la propia artista en su página web hoy desactivada tras la finalización de plazo de propiedad del sitio web. Matías Máximo ha realizado un excelente trabajo al compilar la gran mayoría de las imágenes de la obra en un libro titulado Que el mundo tiemble. Cuerpo y performance en la obra de Effy Beth (2016), editado por la Universidad Nacional de La Plata y disponible online para su descarga aquí: http://sedici. unlp.edu.ar/handle/10915/57876. Gran parte de su obra puede consultarse también en un blog matriz en donde se habían reunido sus proyectos antes de tener su página web: http://tengoeffymia.blogspot.com.ar

3 El proyecto se encuentra relevado en el blog de la artista con el mismo nombre: www.nuncaserasmujer.blogspot.com. Un análisis exhaustivo de dicha obra se encuentra en el artículo "Prácticas artísticas trans: estrategias ex -céntricas para hacerse un cuerpo propio" (Farneda, 2016b). 
También allí aparece publicado un video del año 1964, en donde la cantante Esther Ofarim interpreta Split Personality ${ }^{4}$ (Beth 2009-2011, entrada 7 dic. 2009), la canción de una sirena que, como su título lo indica, vive partida en dos, a la mitad, dividida entre la tierra y el mar. En esta escritura íntima, Effy cita parte de la letra de la canción dado que evidentemente logra expresar algo de lo que la artista intenta narrar: "Half I'm land and half I'm sea / Half I'm it and half I'm she / What a shame it is to be / Such a split personality [...]. No one knows the real girl inside me / Because of all my dreams, I wonder... / Where's the he for this mixed up she / Fish or man who will marry me?" ${ }^{5}$

La cadena de relevos que podemos rastrear en torno a la imagen de la sirena resulta interesante para comprender tanto sus citaciones como sus desviaciones. Este relato aparece resignificado en la escritura de Effy Beth, como una apropiación torcida y extrañada de un producto de la cultura de masas. Esther Ofarim es una cantante israelí reconocida internacionalmente y sobre todo en Europa. En 1964 participa como invitada de un popular programa de la televisión alemana llamado Die Rudi Carrell Show, donde interpreta a una sirena que visita a Robinson Crusoe varado en la isla. Entre ellos surge el amor, pero pertenecen a mundos distintos y la sirena desaparece en el momento en que Crusoe ve acercarse un barco que vendrá en su rescate; él deberá partir sin ella. En este sentido, aunque de manera simplificada, el relato reproduce el conflicto de la narración original del cuento de hadas La sirenita, publicado en 1837 por el escritor danés Hans Christian Andersen, en el cual una sirena, enamorada de un príncipe, se ve imposibilitada de concretar su amor por provenir ambos de reinos diferentes.

A partir de esta cadena, es posible extraer algunos de los rasgos característicos que fundan la estructura romántica de lo que llamaré la matriz teratológica moderna. A través de narraciones como la citada, y emblemáticamente en Frankenstein (1818), la novela de Mary Shelley, el romanticismo ha explorado el conflicto de un mundo crecientemente racionalizado, desencantado, en el cual lo reprimido y lo negado retorna encarnado y corporizado en la figura de una serie de monstruos y seres singulares, cuerpos que presentan un exceso, un derrame inclasificable para los discursos ordenadores. ${ }^{6}$ Uno de sus rasgos característicos es dar voz a la imaginación en oposición a una fe desmedida en la razón, propia de la Iilustración. El romanticismo pretende expresar así las fuerzas de la naturaleza, pero no ya una naturaleza mensurable y cuantificable, sino en los límites de sus potencias, allí en donde el encuentro con la naturaleza produce la experiencia de lo sublime, un encuentro con lo maravilloso y

\footnotetext{
4 http://effyminelaserie.blogspot.com.ar/2009/12/iq-results-high-if.html

5 La traducción realizada por Effy Beth es la siguiente: "Mitad soy tierra y mitad soy mar / mitad soy eso y mitad soy ella / qué lástima es ser así / tal doble personalidad. / Nadie conoce a la verdadera chica dentro mío / Por todos mis sueños, me pregunto... / dónde está él para esta mezcla de ella / pez u hombre quién se casará conmigo?" (En la misma entrada del blog indicada en nota 5).

6 Para un desarrollo de la noción de desasosiego romántico puede consultarse Mitcham.
} 
también con lo terrible y desconocido que acecha; con lo ominoso. Es posible afirmar que, a través de lo monstruoso, el romanticismo expresa procesos de singularización que son narrados de manera siniestra y develadora.

Como es sabido, el romanticismo ha sido un canto a la individualidad, a la singularidad y a la distinción respecto de la norma. ${ }^{7}$ Los protagonistas de estos dos clásicos relatos románticos mencionados se encuentran expulsados de un mundo que anhelan, distanciados de la posibilidad de un amor y pagan el precio de su deseo con sufrimiento, soledad, y finalmente con la muerte. El rasgo que en ambos casos (tanto en La sirenita como en Frankenstein) condena a los personajes es fundamentalmente la singularidad de sus cuerpos. ${ }^{8}$

\section{Encuirar el relato romántico}

La paradoja atrae; la práctica de la crítica queer es lúdica; el juego va en serio, pero nos divierte jugarlo.

Amy Kaminsky

Sabemos que la estructura del amor romántico sobrevive en nuestras concepciones más naturalizadas, transformada y modulada por la cultura de masas. Tanto la canción como la historia narrada en el programa de Rudi Carrell repiten la experiencia romántica de la matriz teratológica moderna, ya en una cierta idea del amor y en la imposibilidad de su concreción, como en las fuerzas sobre-naturales que producen un cuerpo singular, fuera de las normas y de las convenciones anatómicas y culturales. Effy Beth hereda esta cadena significante y se liga a ella en muchos sentidos, pero a su vez la pone a funcionar para expresar nuevas realidades: las de un cuerpo trans que convierte su monstruosa singularidad en signo de una posibilidad, la de devenir un cuerpo deseado y deseable. En estas primeras utilizaciones de la imagen de la sirena, Effy Beth opera una estrategia queer.

Como refieren Butler (313) y Preciado (“Queer. Historia de una palabra”; Testo Yonqui), la reapropiación por parte de los colectivos de desobediencias sexuales y genéricas del término queer (en inglés, raro, torcido, desviado) desde los años ochenta

7 Para una profundización acerca del movimiento romántico alemán en el arte y la literatura, así como su clima de época y sus contextos sociopolíticos, ver Safranski.

8 Aunque la novela de terror moderna es un género complejo y poco delimitable, encuentra muchas de sus raíces en la novela gótica de finales de siglo xviII y comienzos del Xıx, uno de los géneros románticos por excelencia. En la clave de la singularidad corporal pueden ser pensados los protagonistas de muchas otras novelas clásicas de terror decimonónico además de Frankenstein, como puede ser Drácula (1897), de Bram Stoker o El extraño caso de Dr. Jekyll y Mr. Hyde (1886), de R. L. Stevenson, e incluso figuraciones como las del hombre lobo o los licántropos, aparecidas en novelas como La marca de la bestia (1890) de Rudyard Kipling. 
funciona como una subversión, en la lengua inglesa, de una expresión injuriosa que hasta ese momento no significó más que vergüenza y discriminación, pero que logró convertirse en una resistencia activa y creativa de prácticas y pensamientos. Nace no solo ligado a las militancias y resistencias frente al sIDA y el abandono del Estado por el cual las poblaciones afectadas pasaron, sino también como modo de cuestionamiento a la instalación y masificación de un circuito identitario sexual-genérico, clasista y racista: la subcultura gay blanca de clase media y alta, desesperada por presentarse como normal, digerible, asimilable y, de manera fundamental, como económicamente productiva (productora-consumidora).

Desde este contexto, en que lo queer emerge como una serie de movimientos sociales y políticos, no han dejado de proliferar reflexiones, producciones intelectuales y teorías que pretenden bordear y dar cuenta de la complejidad de un término que se presenta de por sí como postidentitario. Más allá de las definiciones fijadas y prefijadas respecto al sexo, al género, al cuerpo y a los deseos, no reniega necesariamente de la identidad o las identidades, pero sí de su asunción esencialista, fija y moralizante. La noción ha encontrado además una proliferación en el campo de los estudios culturales, la crítica literaria y los estudios sobre la subjetividad, ${ }^{9} \mathrm{y}$ ha sido de gran utilidad para repensar y cuestionar la producción misma de las categorías con las cuales abordamos los problemas de investigación.

En este sentido, hago referencia a lo que más arriba nombré como una estrategia queer que la artista Effy Beth pone en marcha: lo queer deviene un modo de leer, torcer y reapropiarse de un canon y un acervo cultural, desplegando allí nuevas realidades y nuevos problemas para hablar del presente. Así, tanto el imaginario romántico moderno como la cultura de masas contemporánea son utilizados para expresar nuevos fines. En estas operaciones de producción de sentido, tampoco se trataría de encontrar lo torcido o lo sexual oculto en los discursos históricos, como si un sentido se encontrara allí enterrado, cual verdad presta a ser liberada ante la lectura -ahora sí atenta- de una cierta crítica cultural. Más bien se trata de comprender la tensión compleja entre una época (la nuestra) y sus pasados, las actualizaciones de una serie de virtuales que se producen en toda creación presente. En esta primera escritura, la artista asume el deseo de encontrar un amor que la complemente o la realice ("pez u hombre ¿quién se casará conmigo?”), y en este sentido no parece cuestionar eso que llamo matriz teratológica romántica, pero al mismo tiempo inscribe ese deseo en una nueva combinatoria corporal y cultural.

Amy Kaminsky nos invita a pensar esta estrategia en clave verbal, y a operar dicha torsión sobre la propia palabra queer: queerizar podría ser el acto de enturbiar e incluso pervertir los sentidos claros y distintos sobre los cuerpos, los relatos y las

9 Hay una gran cantidad de bibliografía sobre el tema. Además de los textos ya mencionados de Judith Butler y Paul B. Preciado, pueden consultarse Wittig, Haraway, Flores, Córdoba y Sáez, Szurmuk y McKee Irwin. 
producciones artísticas y culturales, volver a mirar las operaciones de sedimentación, las imposiciones naturalizadas de sentidos sobre dichos cuerpos y relatos. Para esto, la autora incluso nos propone un juego en la traducción, el neologismo "encuirar": "Reminiscente del verbo encuerar y evocador del acto de desnudar, encuirar significa des-cubrir la realidad, retirar la capa de la heteronormatividad. Propone desvestir no solamente para mostrar la realidad debajo de la vestidura engañosa -el outing clásico-, sino también como una forma de deconstrucción" (879).

En estas apropiaciones latinoamericanas también se pone en juego la transcripción sudaca de dicha palabra y aparece, en reflexiones de la pensadora neuquina valeria flores, ${ }^{10}$ como lo cuir. Como la autora señala, no tiene sentido preguntarse qué es, sino siempre y más bien "cómo hacer funcionar lo cuir en un régimen de escritura" (54). La expresión busca una apropiación y una parodia de la misma institucionalización de lo queer en los regímenes académicos y las teorías en boga en las universidades tanto del norte como del sur, e incluso de esa apropiación centralizada en sus usos porteños cool en relación con experiencias, militancias y pensamientos en otras regiones de Argentina.

Es deseable que lo queer/cuir funcione como una estrategia y una operación, y las escrituras y performances de Effy Beth ponen en marcha dichas per-versiones.

Si lo queer/cuir entonces es una estrategia de torsión, también es, como señalamos más arriba siguiendo a Butler y Preciado, una experiencia de apropiación de la mirada ajena y extrañada. Esta experiencia también se expresa en performances como Soy tu creación (Beth 2011) en donde la artista se presta a la mirada colectiva y se la apropia. Este trabajo denominado como una instalación-performance-interactiva fue elegido para ser presentado en la tercera edición de la Semana del Arte Contemporáneo de Mar del Plata (2011), y tuvo luego varias reediciones en distintas partes del país. En esta performance, Effy ocupó una de las salas de la muestra con un colchón con sábanas, preparado como una cama, y se acostó allí en ropa interior. En el mismo lugar se encontraban papeles, lápices y bolígrafos. En posición relajada simulaba máxima intimidad y se predisponía a entablar conversación con quien sea que se le acercara, solicitando que se la retratara de manera simple y para poder verse a través de todos esos otros ojos.

Aproximadamente 300 personas participaron de manera activa dibujando un retrato de mi persona donde me manifesté no solo como un producto forjado por mí misma y mis experiencias, sino por la aprobación y desaprobación de los desconocidos que entran en contacto conmigo, haciendo un juego de dualidad donde el verdadero artista es el público, y yo solo una obra expuesta y dispuesta a ser interpretada por la subjetividad de una mirada colectiva (Beth 2011).

10 Conservo su nombre y apellido en minúscula, tal como la autora se denomina. 
A partir de aquí Effy reúne esas producciones en un libro de artista llamado Mira Colectiva. Este proyecto llegó a estar compuesto por más de ochocientos dibujos que aparecen publicados en el blog. Effy afirmaba que los dibujos no la reflejaban a ella, sino que expresaban la heterogeneidad de modos de ver que habitan lo social:

Yo les exigía que dejaran de ser público y se constituyeran en artistas. Muchos me contestaban "no, pero yo dibujando soy muy malo" a lo que yo respondía, “ino importa! Yo en la cama no soy muy exigente!” y eso era una manera de introducir humor para que entraran en la performance. (...) Esos dibujos no hablan necesariamente de mí, sino de cada uno de ellos, en el dibujo uno pone un montón de sí. Yo mantenía una pose y un rostro serio, pero en los dibujos aparecía siempre diferente, muy tetona (y yo no lo soy), o muy sonriente y yo estaba seria; me cortaban la cabeza, o me hacían con florcitas, me hacían con barba... entonces cada dibujo hablaba de distintas representaciones sociales, por ejemplo de la transexualidad, de lo desconocido... Yo estaba brindando un espacio de elaboración personal para cualquier persona, sea cual sea su acercamiento con la temática trans... ahí tenían un papel para expresar eso, entonces se genera un registro muy lindo, y sociológico sobre cuál es esa construcción de feminidad, de cuerpo, de identidad, de sexualidad.... ${ }^{11}$

En su blog de artista, Mira Colectiva, es posible observar algunas de estas representaciones. Especialmente allí la artista selecciona y resalta aquellas en las que ha sido retratada como una sirena.

La imagen de la sirena entonces no es solo aquella que Effy desea y se da para sí misma, sino un modo en que también es mirada y deseada, una imagen a través de la cual el cuerpo es entendido y sentido como extraño, partido y recompuesto de fragmentos heterogéneos, fragmentos que pertenecen a distintos mundos, en este caso la tierra y el mar, sin dejar por esto de ser atractivo y deseable, al menos en la imagen moderna que conservamos de la sirena. ${ }^{12}$

Como un relevo de estas particiones sirenaicas es posible leer uno de los cómics realizados por la artista dentro de su serie Transita Rápido (2012) y publicado en un blog que lleva ese nombre (http://transitarapido.blogspot.com.ar). Allí puede verse también la operación de lectura que recae sobre los cuerpos travestis, trans, ambiguos, andróginos o simplemente "poco claros y distintos", demasiado feminizados si son socialmente considerados masculinos, demasiado masculinizados si son socialmente considerados femeninos.

La partición aquí se ve lateralizada, y dialoga con el imaginario sirenaico de pertenecer a dos mundos y ser extranjera siempre, sea cual sea el lugar donde el

\footnotetext{
11 Registro personal de la presentación de Effy Beth en el marco del Seminario de Salud Comunitaria con perspectiva de Género y Diversidad realizado en la Universidad Nacional de Lanús, 15 de mayo de 2013.

12 Sabemos que en los mitos antiguos las sirenas aparecen como seres horripilantes. Exploraré más adelante estas imágenes.
} 


\section{FIGURA 1}

Muchas personas agregaban elementos simbólicos o mágicos, como estrellas, agua, luz o fuego. Alrededor de 12 personas me retrataron como una sirena. Algunos ejemplos:

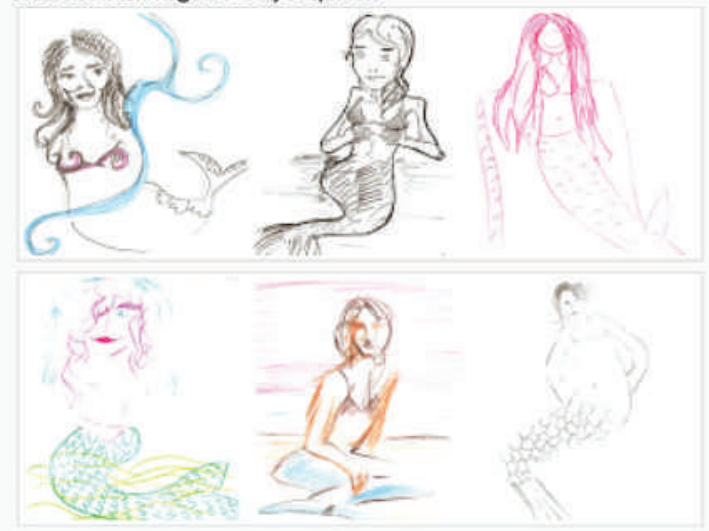

Effy Beth retratada como sirena en el proyecto Mira Colectiva.

\section{FIGURA 2}

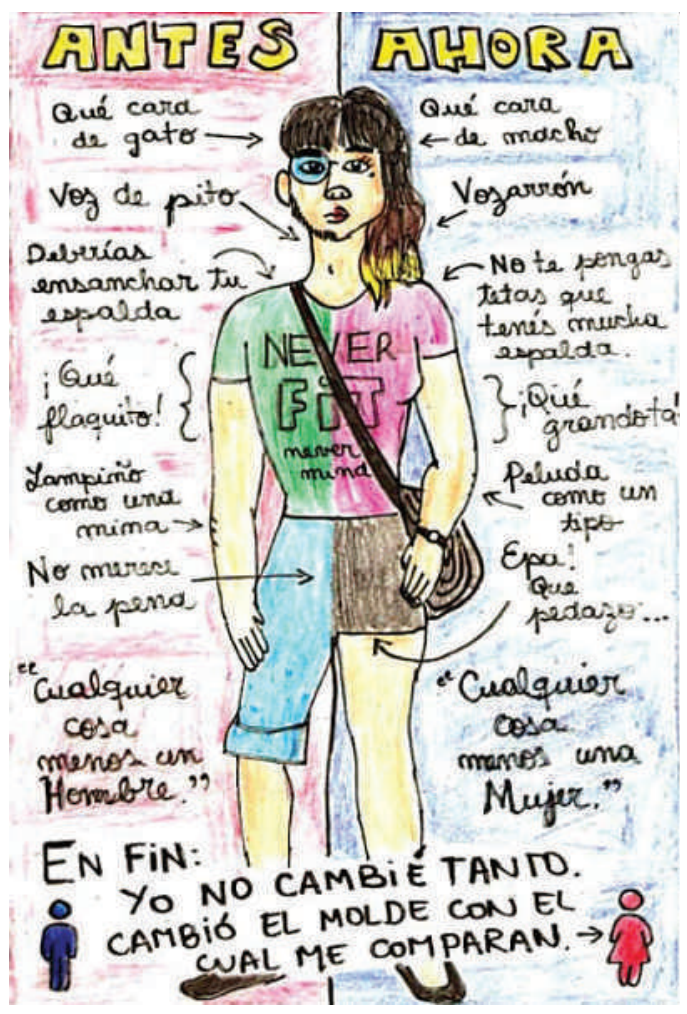

Effy Beth. Cómic no 15 ,

"Sobre Moldes" de la serie Transita Rápido, 2012. 
cuerpo se encuentre y se ubique. La imagen de la sirena entonces se vuelve un vector de existencia, en tanto permite concebir y comprender la presencia de mundos heterogéneos en el propio y mismo cuerpo. Así, dicha imagen se vuelve mitopoiética, un relato y una imagen creativa, reapropiativa, habilitadora.

\section{Lxs monstruos toman Disneyworld}

Desde el clásico de H. C. Andersen a una de las películas más taquilleras y exitosas de los Estudios Disney, la sirenita impregna el imaginario de la industria cultural y aparece reapropiada en los relatos biográficos, las estéticas kitsch y las utilizaciones camp de Elizabeth Chorubczyk.

El film La sirenita, producido por Walt Disney Pictures en 1989, pasó inmediatamente, desde el momento de su estreno, a formar parte del imaginario infantil, integrándose a los íconos de las generaciones que crecen en la década de los noventa. La infancia de Effy no será la excepción. La artista, nacida en 1988, vive sus primeros años en Israel, y para narrar algunas de sus experiencias infantiles produce y presenta en 2012 una video-performance en ocasión del día del niño, en donde compila distintos fragmentos de videos caseros filmados por sus padres durante su niñez, antes de su mudanza a Argentina.

Esta video-performance se titula Pequeña Elizabeth Mati (Little mermaid doblado al castellano) y muestra situaciones familiares y cotidianas, pero seleccionando significativamente los momentos en donde, a través de juegos y diálogos, se exponen las marcas del género sobre los cuerpos de la infancia, los llamados de atención, los señalamientos, desde los actos más inocentes, como describir los juguetes y los juegos, hasta la mostración explícita de los genitales. ${ }^{13}$ Si bien los diálogos se encuentran mayormente en castellano, algunas expresiones y frases aparecen en hebreo. El video se encuentra enteramente subtitulado en castellano y cuenta además con algunos carteles aclaratorios de situaciones.

La singularidad del trabajo que realiza Chorubczyk con los subtítulos radica en lo siguiente: cada vez que es nombrada por sus padres y familiares con el nombre hebreo "Mati", la artista subtitula con su nombre "Elizabeth". A su vez, cambia los pronombres y el género de las palabras al femenino cuando hacen referencia a ella. En algunos momentos su padre le solicita reiteradas veces que muestre el pene (el "pito"), la cola, que orine a cámara, que exponga su miembro, y él se muestra orgulloso de filmarlo y exhibirlo. Cada vez que Elizabeth es requerida a mostrar su pene

13 Algo así como una "marca generacional" emerge en los relatos de muchos varones nacidos entre la década de los setenta y de los noventa en cuanto a las fotografías y filmaciones de los padres (varones), exponiendo y/o explicitando los genitales masculinos de los hijos. Un famoso tipo de fotografías se multiplica en los álbumes de nuestras infancias: el niño en la bañadera, desnudo, y sostenido por los brazos presuntamente de las madres, expuesto a la mirada de la cámara orgullosa, más que lúcida. 
ella subtitula "concha". Cada vez que su padre le habla de sus "bolas", ella subtitula "ovarios". Sin ocultar los rastros ni las marcas de quien fuera en su infancia, la artista produce una tachadura y una torsión sobre los nombres, el cuerpo y los mandatos: conserva y a la vez transforma los fragmentos de su biografía. ${ }^{14}$

Pero la lectura que convoca este video aquí radica en el último fragmento que Effy selecciona para concluirlo. Todavía viviendo en Israel, en casa de su abuela y a la edad de cuatro años y medio, Mati es filmado por su mamá mientras ella le pregunta si quiere cantar como "la sirenita", refiriéndose al film de Walt Disney. En dicha película, el personaje de la sirenita, llamado Ariel (nombre genéricamente indefinido también), realiza un pacto con Úrsula, la bruja del mar, quien es la única que puede convertirla en una verdadera mujer, con piernas (y vagina, cosa que el film no aclara, pero aparentemente eso no es necesario), para que pueda reencontrarse con el Príncipe y seducirlo. A cambio, Ariel debe entregar su voz a la bruja del mar, en una escena en donde tararea una melodía para que la bruja la capture. Frente a la invitación de su mamá a cantar, Elizabeth-Mati entona la melodía que corresponde a aquella escena. Esta información aparece aclarada también en los subtítulos. La video-performance es subida al canal de Youtube de la artista y replicada en sus blogs para conmemorar el día del niño, el 12 de agosto de 2012, con la siguiente leyenda:

Video que recopila imágenes clave de mi infancia en Israel en torno a la Guerra del Golfo y mi cuerpo. Mi regalo hacia ustedes por el Día del Niño. Para que en este día reflexionemos sobre la sexualidad infantil, la identidad de género en la infancia, las presiones/mandatos sociales ejercidos desde antes de nacer, el maltrato y el abuso que no siempre tiene que ser carente de afecto, perverso o violento para ser violencia. ${ }^{15}$

Los relatos de Chorubczyk enlazan y se apropian de las figuraciones sirenaicas, esas que encuentra en la cultura de masas y que le sirven a la artista para tramitar, negociar sentidos, abordar experiencias, nombrar y pensar la posibilidad de un cuerpo deseable. El rasgo de la voz que la película pone de relieve no es indiferente, dado que es allí también, y no solo en la apariencia visual, donde se operan procesos de normalización, corrección y ortopedia de las identidades. La propia voz puede devenir en el elemento de mayor exposición, el punto de inflexión del simulacro de la imagen. La voz expone al cuerpo y lo abre al encuentro de una manera diferente a como lo hace la mirada. En este caso, la sirenita negocia la posibilidad de ser una mujer "verdadera" a cambio de su voz y, claro está, a cambio de la posibilidad de decir. Monstruoso es,

14 En la tesis doctoral "Prácticas de Sí: subjetividades contemporáneas en las expresiones artísticas trans actuales", defendida en la Facultad de Filosofía y Letras (UBA), Farneda realiza un extenso análisis de este trabajo de traducción y tachadura respecto al nombre propio, los procesos de apropiación del nombre y del cuerpo, a partir de lecturas de Derrida y Nancy.

15 El video y este texto se encuentran disponibles en: http://tengoeffymia.blogspot.com.ar/2012/08/pequena-elizabethmati.html 
más que los cuerpos anormales, el proceso de normalización por el que los cuerpos pasan para volverse "naturales".

En la exposición y parodización de estos mismos procesos, Effy publica una serie de cómics en su página privada de Facebook ${ }^{16}$ en donde aparece, otra vez, la sirenita de Disney. Luego de haber conseguido sus piernas para poder ir en busca de su príncipe Eric, pero con un pene que sobresale del agua, el pelícano de la película le dice: “¿Así que la Bruja del mar te quitó la voz para que Eric no se diera cuenta de que naciste sin vagina? Bueno, ahora habrá que taparte con algo, ¿no?”

Aquí Effy deja de presuponer que, además de piernas, la bruja le otorgue a Ariel una vagina, y produce incluso una variación en esa presuposición naturalizada: estrictamente hablando, nada impide imaginar que Úrsula haya podido darle un pene en vez de vagina.

El cuerpo entonces es continuamente el enigma de la normalidad, aquello que una y otra vez escapa a la imagen idealizada: sin voz, pero con piernas. Con piernas, pero sin vagina; con vagina, pero sin voz... El "sexo" y el cuerpo no se presentan como un sustrato natural sobre los cuales los géneros y las identidades se dan culturalmente o se construyen subjetiva o socialmente. En términos de Judith Butler, el sexo es ya un ideal regulatorio cuya materialización se impone o se logra (o no) mediante la reiteración de ciertas prácticas sumamente reguladas [...]. [Pero] que esta reiteración sea necesaria es una señal de que la materialización nunca es completa, de que los cuerpos nunca acatan enteramente las normas mediante las cuales se impone su materialización" (18).

En esta reflexión, Judith Butler nos brinda la pista de un resto, de un movimiento entrópico que desafía la sedimentación de los cuerpos y las identidades, sus procesos de materialización. A través de las figuraciones sirenaicas, Effy capta y expresa este proceso de movimiento continuo, este desacato de los cuerpos, sus enigmas, la impronta y la fuerza de su desclasificación.

Que lo monstruoso sea lo característico de la normalidad no es una paradoja, más bien al contrario, y en un doble sentido que exploraré a continuación. Por un lado, lo monstruoso es inscrito en la modernidad como su otro, funciona como réplica y sombra de la llamada sociedad disciplinaria o sociedad de normalización (Foucault, Los anormales; Vigilar y castigar). También Butler explorará en este mismo sentido el término abyección (19-20), trazando una cierta continuidad con la categoría psicoanalítica de forclusión y dando cuenta, en esa conexión, de una operación desestructurante que posee lo abyecto en relación con el campo social, una amenaza de desestabilización. En este sentido, nuestro campo social se constituye eyectando, expulsando los cuerpos y las subjetividades que por el régimen de normalización devienen insoportables, constituyendo así zonas inhabitables, vidas precarias, cuerpos

16 Material solo parcialmente incluido en su blog. 


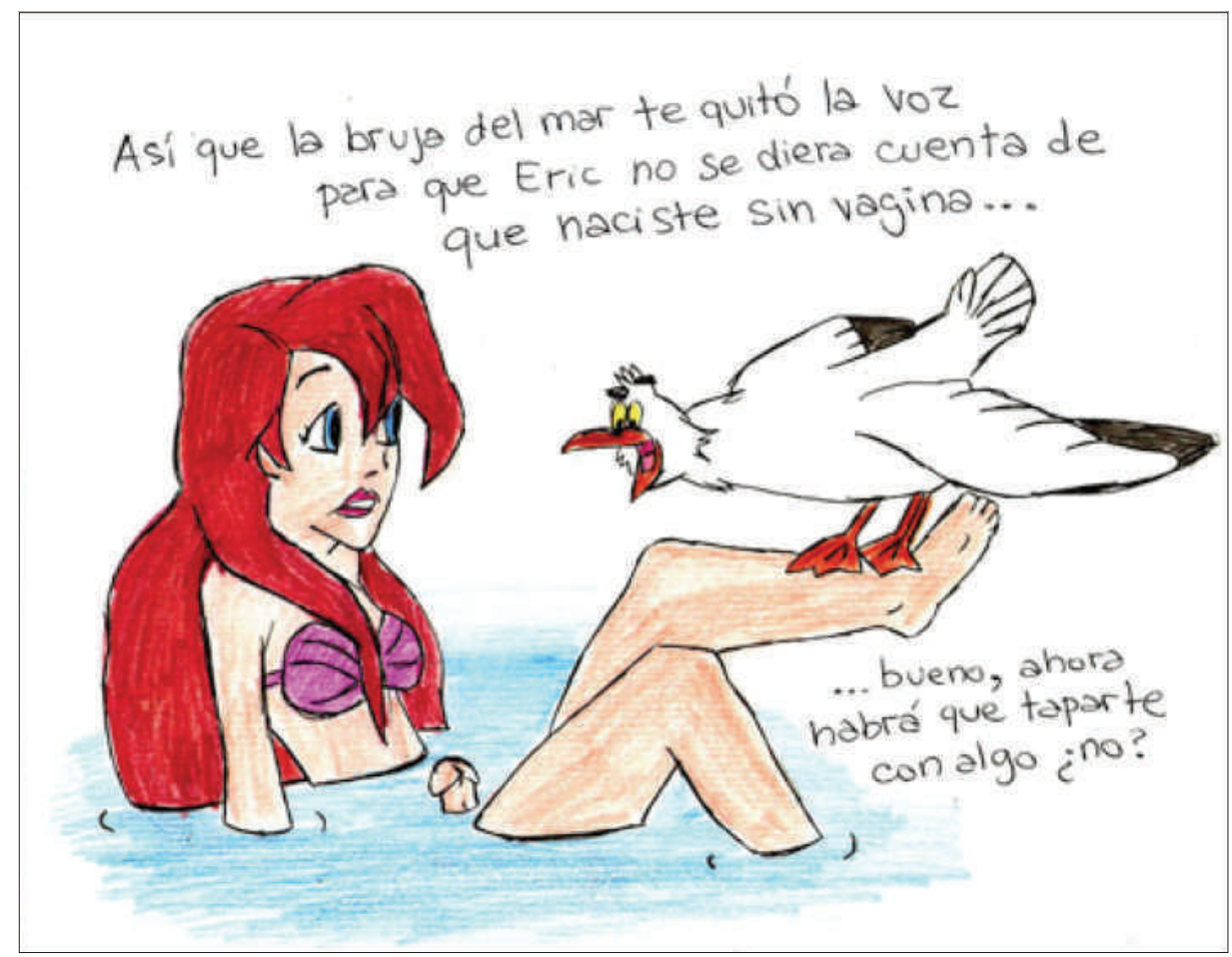

Foto subida en la página web personal de Elizabeth Chorubczyck.

que no importan. Por esta misma razón, la normalidad es también monstruosa: no hay esencia que dictamine aquello que será arrojado al territorio inhabitable de lo abyecto ni que establezca parámetros de una "verdadera" existencia normativizada a priori o ad eternum: siempre es un proceso histórico y social el que establece como normal algún tipo de singularidad en oposición a otro tipo o a una serie de singularidades cualesquiera. La normalidad es una monstruosidad convencionalizada.

\section{Teratologías y desclasificaciones}

La teratología puede definirse como el estudio de los especímenes que nacen por fuera de una supuesta norma biológica atribuida a la naturaleza. ${ }^{17}$ Como señala Claudia Kozak, el sentido etimológico del término y su acepción cotidiana ubica a lo monstruoso como aquello que "muestra" (en latín: ego monstruo - "yo muestro"-, del verbo

17 La definición que presenta el diccionario de la RAE es: "estudio de las anomalías y monstruosidades del organismo animal o vegetal”. Se encuentra clasificado de este modo, en tanto disciplina científica, como una rama de la zoología. 
monstrare), pero también podría tener una raíz en el sentido de advertir: "(monere); una advertencia de los dioses respecto de las posibilidades de lo existente" (5).

Aquí, en nuestras prácticas abordadas, estas anomalías son explícitamente sondeadas, y expresan la posibilidad de ser deseables y deseadas, abren nuevas orientaciones del deseo en cuanto a los propios cuerpos.

En vinculación con las figuraciones sirenaicas de Effy Beth, es necesario retomar los análisis de Daniel Link sobre los fantasmas, monstruos y sirenas como potencias de desclasificación que operan en la relación entre imaginación y sociedad: "Llamo fantasma a una 'figura difícil de asir' [...]. Los fantasmas tienen su potencia y esa potencia es una fuerza de desintegración [...] nunca un límite, siempre un umbral" (Link 11-3).

Si en un sentido ontológico entonces la esencia del ser es existir, no puede decirse que los fantasmas sean, dado que no alcanzan un estatuto de existencia. A través de sus potencias, estas figuras más bien subsisten e insisten, molestan, encarnan las ansiedades de una época, sus temores, lo que esa época tiene de terrible, de intempestivo y de creativo. ${ }^{18}$ Allí Link cita a Blanchot:

\begin{abstract}
¿Acaso las sirenas, como la costumbre nos ha intentado persuadir, eran únicamente las voces falsas que no había que oír, el engaño de la seducción...? Siempre ha existido en los hombres un esfuerzo poco noble por desacreditar a las Sirenas acusándolas simple y llanamente de mentira: mentirosas cuando cantaban, engañosas cuando suspiraban, ficticias cuando se las tocaba: inexistentes en todo, con una inexistencia pueril que el sentido común de Odiseo bastó para exterminar (cit. en Link 15).
\end{abstract}

Sin embargo, aunque mentira, la sirena aparece como una mentira peligrosa, de la cual Odiseo debe proteger a sus marinos, hombres trabajadores, tapándoles los oídos para que no oigan sus cantos. Ya esta primera imagen de la sirena se asemeja a la tensión desplegada sobre los cuerpos travestis cuando son en la ciudad, como señala Martín Boy, cuerpos que repelen pero que a la vez gustan y que atraen, y se vinculan con los relatos sobre las zonas rojas: sirenas mentirosas en todo, que sin embargo desatan en el campo social el deseo de su propia mentira.

Rescatando imágenes griegas, judeocristianas e indoamericanas, Daniel Link (21) reconstruye diferentes figuraciones sirenaicas, desde aquellas griegas consideradas como mitad mujeres y mitad pájaros, con plumas y garras, hasta, desde el siglo vi de nuestra era, la concepción de un cuerpo que en parte es de pez. Señala que han sido asociadas muchas veces a divinidades como las musas, nereidas e incluso a los tritones, pues en ocasiones se las ha descrito con barbas o cantando con voces masculinas. De

18 En este sentido, El fantasma de Canterville de Oscar Wilde parece ser el extremo de un fantasma que pierde su potencia, deja ya de molestar o de encarnar las ansiedades de una época. Reflexionando en los términos de Daniel Link, podríamos decir que entra en un sistema de reconocimiento, de re-clasificación. 
ahí que, para el autor, estos seres no pueden ser naturales pero tampoco sociales, y su canto tampoco debe identificarse totalmente con lo imaginario:

No están ni en lo Real (lo Natural) ni en lo Imaginario (los delirios narcisistas de identificación) ni en lo Simbólico (la estructura social entendida como sistema de clasificación o como dispositivo de interpelación): son monstruos. La modernidad normalizadora y clasificadora no pudo lidiar con alegría con ese “entre-lugar"[...]. Están, esos todavía-no-cadáveres (morituri perpetuos), en lugar de nada, en un umbral entre naturaleza y cultura (26-35).

Estas exploraciones teratológicas encuentran resonancias con la noción filosófica y estética de lo monstruoso que Peter Sloterdijk desarrolla para pensar la condición humana como apertura monstruosa de claro, como incertidumbre y exceso, creación y expansión de nadas que son entes, híbridos, cruces entre las viejas categorías ontológicas de naturaleza y artificio. Así, el pensador nos invita a observar "lo monstruoso hecho por el hombre" de manera ambivalente y problemática: nuestra época es una época (criminal) de lo monstruoso porque expone todo lo que podemos, porque lo terrible y lo sublime que acontece no es atribuido ya al mundo de los dioses, sino que, para usar su propio lenguaje heideggeriano, ${ }^{19}$ constituye la propia relación de lo humano con su claro.

Lo monstruoso es claro, apertura, y a la vez errancia criminal. Exceso, desmesura, desproporción. Y esto monstruoso que constituimos (en tanto lo hacemos) y acontece (en tanto nos constituye) no puede ya ser entendido con el lenguaje occidental de la moral maniquea (bueno-malo) ni de la metafísica clásica, en donde las dimensiones del sujeto y del objeto, del espíritu y de la materia, de la cultura y de la naturaleza, han sido pensadas como particiones, y en compartimentos estancos.

Esta metafísica clásica, de la cual percibimos un cierto agotamiento, es descrita por Sloterdijk como una ontología monovalente, en donde, simplemente (o sea de manera simplista), el Ser es y el No-ser no es, regida por una lógica tan solo bivalente en donde lo verdadero no es falso y lo falso no es verdadero (tertium non datur). En dicha matriz lógico-ontológica no es posible ver prosperar la complejidad de los mundos contemporáneos en donde se despliegan entes que son nadas, nadas que son entes, híbridos materiales-espirituales, dualidades onda-partícula, paradojas cuánticas, multiplicidades tecno-orgánicas vivas, cuerpos que son menos y más que naturaleza y artificio.

La división fundamental, propia de la cultura "superior", de alma y cosa, espíritu y materia, sujeto y objeto, libertad y mecanismo resulta inoperante: todos los objetos culturales sin duda son, por su constitución, híbridos con un "compo-

19 En su libro Sin salvación, Peter Sloterdijk (2011) se propone retomar, cómo él mismo lo aclara, un lenguaje heideggeriano para apartarse y producir distancia con dicho autor. Se encuentra en varios momentos de sus artículos algo así como una escritura heideggeriana contra Heidegger. 
nente" espiritual y otro material, y todo intento de decir lo que "apropiadamente" son en el marco de una lógica bivalente y la ontología monovalente termina irremisiblemente en reducciones estériles y restricciones destructivas [...]. La aplicación práctica de estas divisiones es el dominio (141-43).

El lenguaje de dicha metafísica ha relegado al lugar de la nada todo aquello que huye de sus modos de representación, y por este motivo se vuelve fundamental entender la historia de la técnica y el arte, la historia de los artificios y de lo monstruoso hecho por el hombre, como historia creciente de la nada. Dado que el artificio ha sido metafísicamente concebido con desconfianza (desde Platón esto parece ser una constante, según Sloterdijk), como simulacro, como apariencia (espuma, sirena...), este autor pretende reivindicar como vector de pensamiento la nada en tanto dimensión en la que acontece el despliegue de las potencias del arte y la técnica, ese entre-lugar al que se refiere también Daniel Link, en donde la imaginación social puede escapar al reino de lo siempre-igual.

Quien quiera leer la historia del arte y de la técnica como historia del ser sólo puede observar por doquier perecimientos: olvido del ser, fin de la historia del arte concebido como sustancia, caída de la humanidad en lo imposible, formas multimediales para almas muertas. Es preciso dar razón del hecho de que la historia de lo artificial no puede ser ya tratada al estilo de la historia del ser. La cosa artificial -si es pensada desde el ser- jamás podrá ya liberarse de la sospecha de decadencia ontológica y de haber traicionado una plenitud inicial del sentido y del alma (Sloterdijk 252).

Es posible observar aquí, incluso en la escritura del propio Sloterdijk, la dificultad para escapar a los lenguajes naturalizados, y el desafío de producir nuevas torsiones. Cuando en esta cita, por ejemplo, el autor refiere a lo artificial, vuelve a utilizar la palabra "cosa". Sin embargo, considero fundamentales estas reflexiones para abordar un pensamiento comprometido sobre y desde nuestros cuerpos, en las prácticas artísticas y así también en las investigaciones académicas y en las formulaciones epistemológicas. Son los cuerpos los que se despliegan como potencias de exploración de nuevas sensibilidades, nuevas estéticas, nuevos problemas artísticos y científicos. En este sentido, engrosan más una historia de la nada que una historia del ser, y se encuentran por fuera de la dualidad sujeto-espíritu / objeto-cosa-materia.

Las experiencias corporales desplegadas en las prácticas artísticas trans (y verosímilmente las experiencias corporales desplegadas en el arte contemporáneo en general, en el bioarte, en las performances y en la vinculación entre arte y tecnología) rasgan esa dualidad y fuerzan a inventar lenguajes, materialidades y nuevas formas de expresión para narrar otra historia del artificio. Pensar el cuerpo, la materia corporal, como efecto mismo de un artificio, como una nada que deviene, temporal y espacialmente, desmantela la distinción entre natural y cultural, y le otorga a la materia una 
capacidad imaginante, configurante, que la arranca de la condena ontológica a ser simple y solamente res extensa, mera inercia, deudora ontológica. El cuerpo traza su propia cartografía, compone un pensar, un hacer, un despliegue estético comprendido como producción de mundos. Allí no hay nada, no hay esencia ni modelo. Hay fuerzas en tensión, composición y descomposición.

\section{Festejar-T: homenajes a Effy Beth}

Los cuerpos trans aparecen como aquellos que delimitan el cuerpo bien entendido, el cuerpo decodificable, visible, y nos enfrentan con las estrategias con las que dichos cuerpos "naturales" han sido recortados: en una tajante oposición a la ambigüedad, a la monstruosidad, a la animalidad. ${ }^{20}$ Pero para estas prácticas artísticas, las fronteras de los imaginarios culturales donde se tramitan dichos límites, como los animales mitológicos, los monstruos, los zombis, las imágenes escatológicas, devienen potencias de exploración y producción de un propio cuerpo, que hace saltar las imágenes de sus límites y los carteles prefijados.

Para poner en marcha estas operaciones no alcanza con la mirada, y es necesario activar otras formas de afectar y conmover los cuerpos. Con este sentido, tal vez, la muestra homenaje a Effy Beth, luego de su muerte ocurrida en marzo del 2014, se ha llamado Que el mundo tiemble cuando yo no tiemble. Dicha muestra se realizó el 5 de julio de 2014 en el Museo de Calcos y Escultura Comparada Ernesto de la Cárcova, dependiente de la Universidad de las Artes (UNA), donde Effy estudiaba su carrera de artes visuales. Allí se presentaron ilustraciones, dibujos e historietas, fotografías $\mathrm{y}$ videos de sus performances, instalaciones armadas con objetos y textos utilizados por ella, y música. El colectivo de amigxs y compañerxs que lo organizó no dudó en intervenir el espacio y algunas de las esculturas pertenecientes al museo, principalmente una ubicada en el patio, con unas telas bordadas como escamas y una cola de sirena, una de sus figuraciones recurrentes.

En la muestra-homenaje, una de las salas se armó como instalación. Titulada "pecera", recreaba con arena, penumbras y luces en movimiento un paisaje submarino, en donde se veían objetos de la sirenita, y se proyectaba un fragmento de la película contra la pared, aquel en donde Ariel (la sirenita) le entrega la voz a la Bruja del Mar a cambio de que la convierta en una mujer "completa", con piernas, con vagina y sin cola.

La estética de estas instalaciones e intervenciones en el Museo de la Cárcova recurrió insistentemente al kitsch, al desperdicio, al rescate y reutilización de objetos propios de la infancia en los años noventa, como los papeles brillantes, los stickers, y un torcimiento sudaca y reapropiado de la imaginería Disney. El contraste entre la

20 Gabriel Giorgi ha llevado adelante una serie de investigaciones fundamentales sobre biopolítica, cuerpos, géneros y animalidad. 
solemnidad del museo y la intervención resultó extraño y carnavalesco: subvirtió el orden de la institución, llenó esa inmensa casona de anarco-queers, punks, artistas, músicxs, amigxs y familia. El museo fue una fiesta, y la tristeza inmensa. Paradojas del cruce entre arte y vida.

El traje que performaba la estatua en el patio del museo también se encontraba confeccionado con retazos de telas como escamas y bolsas de plástico, y todas las instalaciones parecían buscar y alcanzar el reencantamiento de un mundo que vive de los restos.

La cultura de masas aparecía reapropiada por Effy en sus significaciones, en una compleja elaboración que su homenaje expuso. Un literal revival del llamado arte light de los años noventa, ese arte que bien supo desmantelar las tajantes divisiones entre lo alto y lo bajo, entre materiales nobles y materiales de desecho, que exponía y denunciaba, otra vez, los restos, los bordes y los desperdicios no degradables de las sociedades de consumo, parecía activarse y hacerse presente resignificado por los imaginarios travestis-cuir de sus círculos de afectos. ${ }^{21}$ La parada de los monstruos y lxs desclasados irrumpe en el museo por culpa de una trans que había osado performar e inscribirse en lo más interesante del arte conceptual porteño de los últimos años.

Elizabeth Chorubczyk disputó dentro del campo de las artes, y de sus géneros bien delimitados y definidos, justamente la posibilidad de producir y de ser leída dentro del arte conceptual político sudaca. Como solía decir, "ni diosa, ni princesa", su imagen fue la sirena: un territorio de batalla, una figura que no "existe", pero que insiste y subsiste ${ }^{22}$ en el propio devenir de su imaginería occidental, encantando, emergiendo, perturbando la superficie tranquila y disciplinada de la playa de turistas, incomodando los territorios asignados para los cuerpos trans, buscando su propia voz, esa una vez entregada, un precio demasiado alto para ser, que Effy decidió reconquistar a través de su obra.

\section{Puesta en perspectiva de este trabajo}

A lo largo de toda la obra de la artista Elizabeth Chorubczyk, las figuraciones sirenaicas son una constante, tanto en sus primeras escrituras íntimas publicadas (Effymine), como en sus cómics (Disney Side Story) y en su trabajo de reelaboración de los relatos de infancia en su video-performance (Pequeña Elizabeth-Mati o Little Mermaid doblado al castellano).

21 En este "revival" kitsch y light resuena por ejemplo la fotografía del artista Marcos López, Sireno del Río de la Plata (2002), operando torsiones similares. El sireno retorna, espectral, sobre los desperdicios, la basura y el plástico que se acumula a la vera del río, mostrando desde allí su brillantez: otro retorno sirenaico que interrumpe la matriz teratológica moderna.

22 Deleuze, retomando términos neoplatónicos, afirma que este es el modo mismo de darse el sentido: no existe, pero insiste y subsiste. Es una nada antes que un ente realmente existente, en términos desarrollados antes por Sloterdijk. 
FIGURAS 4 y 5
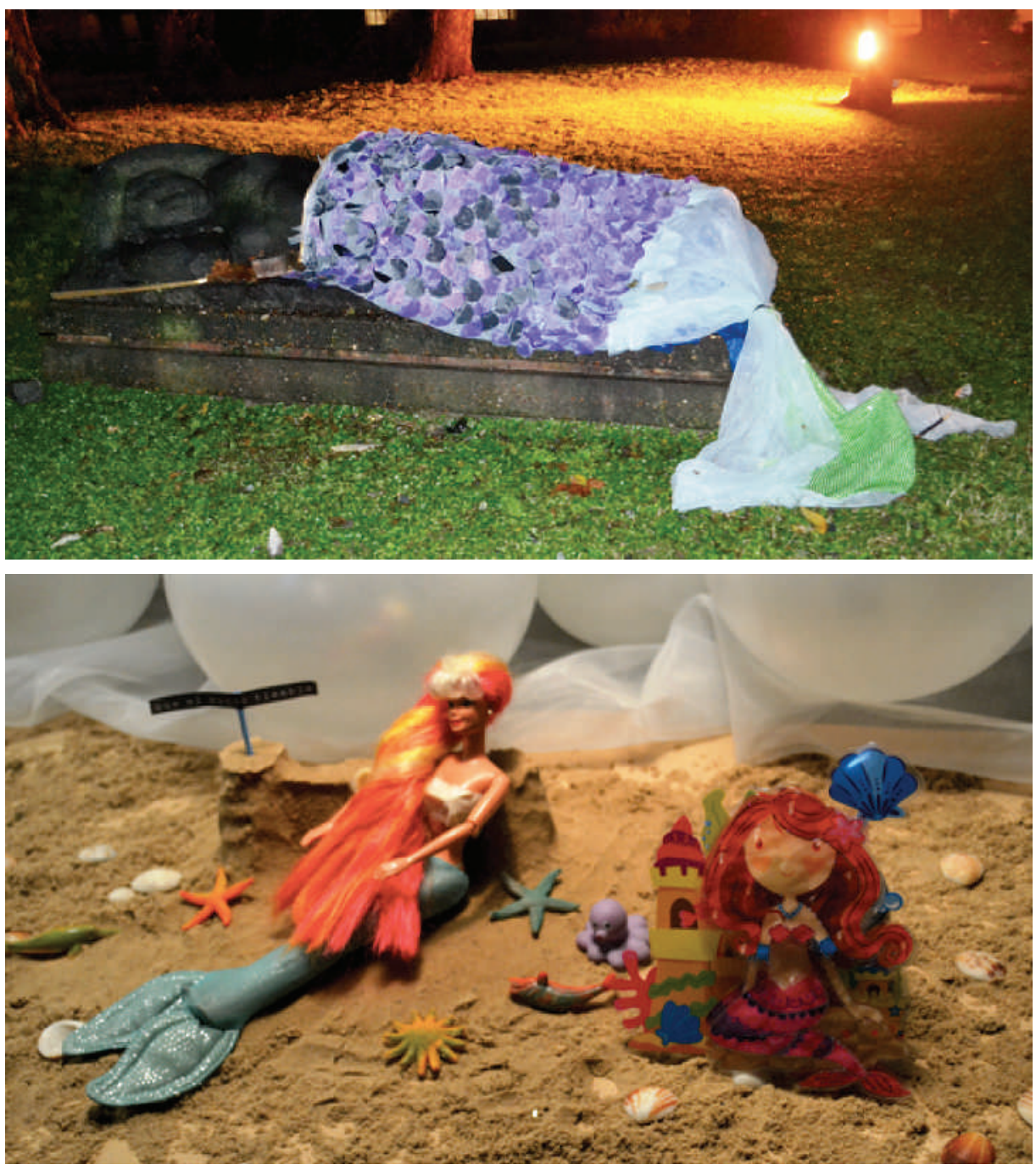

Instalaciones que formaron parte de la muestra "Que el mundo tiemble cuando ya no tiemble. Homenaje a Effy Beth". Museo Ernesto de la Cárcova, 5 de Julio de 2014.

La reapropiación de esta figura pasa en nuestras sociedades por una serie de relevos culturales: estos podrían pensarse en los términos de una supervivencia que no conserva un significado profundo sino más bien el relevo de una fuerza o una serie de fuerzas que adquieren expresión en la situación histórica-cultural en que se despliegan. La imagen de la sirena en el marco del romanticismo europeo encarna una marca perdurable en nuestro modo de percepción, que me ha interesado llamar matriz teratológica moderna: una relación particular de tramitación con las potencias 
de lo monstruoso, lo ominoso, que en la modernidad es sistemáticamente negada y aniquilada, expresándose esta tensión fundamentalmente en las dimensiones del arte y la literatura. Para esta matriz, lo monstruoso es la diferencia anormal, la diferencia que es necesario disciplinar o hacer desaparecer. De hecho, es el fondo contra el cual se recortan las normalidades de los cuerpos y las subjetividades, el cuerpo y el individuo bien entendido. Sin embargo, y paradójicamente, el romanticismo es capaz de dar voz a estas potencias de lo monstruoso, situando y sitiando a sus personajes fundamentalmente por la singularidad de sus cuerpos.

En un relevo de ciertos esquemas narrativos románticos, la cultura de masas del siglo $\mathrm{xx}$ ha tomado y transformado imágenes y relatos del siglo xix. De aquel primer desenlace narrativo en donde la sirena muere por amor (en el cuento original pero también en el programa de Rudi Carrell de los años sesenta), al triunfo del amor heterosexual y del cuerpo normalizado y adaptado (a costa de la propia voz en $\mathrm{La}$ sirenita de Disney), se produce una fuerte adaptación y normalización -valgan las redundancias- de las mismas figuraciones teratológicas.

En fin, la matriz teratológica moderna funciona como un dispositivo de clasificación, readaptación y desentrañamiento que debe resolver las paradojas y complejidades de los cuerpos y las identidades, y en este sentido puede pensarse como la cara oscura de la matriz disciplinaria moderna o como su exacto sinónimo.

Pero a la despotentización de lo monstruoso que esta matriz realiza, los propios monstruos responden activando y explorando sus potencias de desclasificación, como las llama Daniel Link. Las obras de Effy empalman en ciertos puntos con los relatos románticos (cuando refiere al amor, la completitud, su otra mitad), pero a la vez desplazan y cuirifican la imagen de belleza y cuerpo bien entendidos, y son capaces de activar nuevos modos de desear, así como de presentar lo deseado y deseable. A través de sus propias estrategias, las obras desmontan y exponen la matriz teratológica moderna: muestran los peajes, los precios, los costos que los cuerpos pagan para constituirse en cuerpos que importan, para volverse legibles y salir de las zonas de mosntruificación: la voz, la expresión, el propio deseo, incluso partes del propio cuerpo.

A su vez, rechazan la lógica que indica "entrar en la existencia". Prefieren más bien, desde una ontología polivalente, insistir y subsistir, transformar la nada y el no-ser en un territorio de lucha capaz de desclasificar los términos de la inclusión, la existencia y la normalidad. Desde aquí, Chorubczyk ha disputado el campo de la performance y el arte conceptual para sí, abriendo la caja de Pandora, dejando salir y haciendo entrar viejos y nuevos fantasmas que recorren ahora el mundo. 


\section{Referencias}

Beth, Effy. Effymine, la serie, 2009-2011, http://effyminelaserie.blogspot.com.ar ---. Mira colectiva, 2011, http://miracolectiva.blogspot.com.ar/

Butler, Judith. Cuerpos que importan. Sobre los limites materiales y discursivos del "sexo". Buenos Aires, Paidós, 2008. Impreso.

Córdoba, David y Javier Sáez, eds. Teoría Queer. Políticas bolleras, maricas, trans, mestizas. Barcelona, Egales, 2005.

Deleuze, Gilles. Lógica del sentido. Buenos Aires, Paidós, 2008.

Farneda, Pablo. "Prácticas de Sí. Subjetividades contemporáneas en las expresiones artísticas trans actuales, en la ciudad de Buenos Aires". Tesis para optar por el grado de Doctor, Universidad de Buenos Aires, 2016.

---. "Prácticas artísticas trans: estrategias ex-céntricas para hacerse un cuerpo propio", Versión. Estudios de Comunicación y Política, n³7, 2016, pp. 155-171, http:// version.xoc.uam.mx/

Flores, Valeria. Interruqciones. Ensayos de poética activista. Neuquén: Editora La Mondonga Dark, 2013.

Foucault, Michel. Los anormales. Buenos Aires, FCE, 2001.

---. Vigilar y castigar. Buenos Aires, Siglo xxi, 2004.

Giorgi, Gabriel. Formas comunes. Animalidad, cultura, biopolítica. Buenos Aires, Eterna Cadencia, 2014.

---. “Especies especiales”. Suplemento Soy de Página/12, 24 abr. 2015, http://www. pagina12.com.ar/diario/suplementos/soy/1-3950-2015-04-24.html

Giorgi, Gabriel y Fermín Rodríguez, comps. Ensayos sobre biopolítica. Excesos de vida. Buenos Aires, Paidós, 2007.

Haraway, Donna. Ciencia, cyborgs y mujeres. La reinvención de la naturaleza. Madrid, Cátedra, 1995.

Kaminsky, Amy. "Hacia un verbo queer". Revista Iberoamericana, vol. Lxxiv, n² 225, 2008, pp. 879-895.

Kipling, Rudyard. La marca de la bestia. Madrid, Valdemar, 2001.

Kozak, Claudia. "De libros y otras monstruosidades en el dominio digital". III Simpósio Internacional e VII Simpósio Nacional de Literatura e Informática "Livro: do analógico ao digital". Belo Horizonte, Brasil, 9-18 de diciembre de 2014. Universidade Federal Fluminense/CEFET-MG/Universidade Federal de Santa Catarina.

Link, Daniel. Fantasmas. Imaginación y sociedad. Buenos Aires: Eterna Cadencia, 2009.

Mitcham, Carl. “Tres formas de ser-con la tecnología”. Revista Anthropos, n 94/95, 1989, pp. 13-26.

Preciado, Paul B. "Queer. Historia de una palabra”. Revista/Blog Parole de queer, abr.-jun. 2009, http://paroledequeer.blogspot.com.ar/2012/04/queer-historiade-una-palabra-por.html 
---. Testo Yonqui. Madrid, Espasa, 2008.

Safranski, Rüdiger. Romanticismo. Una odisea del espíritu alemán. Buenos Aires, Tusquets, 2012.

Santiesteban, Héctor. "El monstruo y su ser". Relaciones. Estudios de historia y sociedad. vol. xxI, n 81, 2000, pp. 94-126, http://www.redalyc.org/articulo.oa?id=13708105 Shelley, Mary. Frankenstein o el moderno Prometeo. Ciudad de México, Sexto Piso, 2013. Shock, Susy. Poemario Trans Pirado. Buenos Aires, Nuevos Tiempos, 2011.

Sloterdijk, Peter. Sin salvación. Tras las huellas de Heidegger. Madrid, Akal, 2011.

Stevenson, R. L. El extraño caso de Dr. Jekyll y Mr. Hyde. Madrid, Valdemar, 2006.

Stoker, Bram. Drácula. Madrid, Cátedra, 2005.

Szurmuk, Mónica, y Robert Mckee Irwin. Diccionario de Estudios Culturales Latinoamericanos. México, Siglo xxI-Instituto Mora, 2013.

Wittig, Monique. El pensamiento heterosexual y otros ensayos. Barcelona, Egales, 2006.

Enviado: 12 julio 2017

Aceptado: 5 marzo 2018 